
genética e importância de caracteres morfológicos em genótipos de couve. Horticultura Brasileira 32: 48-54.

\title{
Divergência genética e importância de caracteres morfológicos em genótipos de couve
}

\author{
Alcinei M Azevedo ${ }^{1}$; Valter C Andrade Júnior ${ }^{2}$; José SC Fernandes ${ }^{2}$; Carlos E Pedrosa ${ }^{2}$; Nermy R \\ Valadares'; $^{2}$ Marcos AM Ferreira ${ }^{2}$; Rafael AV Martins ${ }^{2}$ \\ ${ }^{1}$ UFV, Depto. Fitotecnia, 36570-000 Viçosa-MG; alcineimistico@hotmail.com; ㄹFVJM, Campus JK, Alto da Jacuba, Rod. MG 367 \\ km 583,nº 5000,39100-000 Diamantina-MG; valterjr@ufvjm.edu.br; carlosenrrik@yahoo.com.br; nermyvaladares@hotmail.com; \\ marcaumife2010@hotmail.com; rafa_montesclaros@yahoo.com.br
}

\section{RESUMO}

A caracterização morfológica de genótipos de couve é necessária bem como as estimativas da divergência genética entre os mesmos. O presente trabalho teve como objetivos estudar os caracteres morfológicos dos genótipos de couve oriundos do banco de germoplasma da UFVJM, a divergência genética existente entre os genótipos e a importância destes caracteres nas estimativas da divergência. $\mathrm{O}$ experimento foi conduzido no Setor de Olericultura da UFVJM, Diamantina-MG, utilizando-se o delineamento experimental em blocos casualizados com trinta genótipos e quatro repetições, constituídas por cinco plantas. Para a caracterização morfológica avaliaram-se em cada planta quarenta e quatro características. Verificou-se que há genótipos com grande divergência genética entre si, sendo os genótipos UFLA-6 e UFVJM-24 os mais divergentes em relação aos demais, contudo, a maioria dos genótipos é similar. Verificou-se também que há características importantes que podem ser usadas nas estimativas da divergência.

Palavras-chave: Brassica oleracea var. acephala, análise multivariada, distância de Mahalanobis, agrupamento de Tocher.

\section{ABSTRACT}

Genetic divergence and importance of morphological characters in genotypes of kale

The morphological characterization of genotypes of kale is needed as well as the estimates of genetic divergence between them. We studied the morphological characters of kale genotypes originated from the germplasm bank of UFVJM, the genetic divergence among the genotypes and the importance of these characters in the estimates of divergence. The experiment was carried out in the Department of Horticulture of UFVJM, Diamantina, Minas Gerais state, Brazil, using the randomized complete block design with four replications and thirty genotypes, consisting of five plants. Forty-four traits were evaluated on each plant for morphological evaluations. Some genotypes showed high genetic divergence, such as the genotypes UFLA-6 and 24-UFVJM, which were the most divergent compared to the others. Most of the genotypes, however, were similar to each other. It was also observed that there are important characteristics that can be used in the estimation of divergence.

Keywords: Brassica oleracea var. acephala, multivariate analysis, Mahalanobis distance, Tocher grouping.

(Recebido para publicação em 29 de Agosto de 2012; aceito em 27 de setembro de 2013)

(Received on August 29, 2012; accepted on September 27, 2013)

\begin{abstract}
A couve (Brassica oleracea var. acephala) é uma das formas mais antigas da família Brassicaceae, originada no leste do mediterrâneo e utilizada para a alimentação humana há mais de 2000 anos a.C (Balkaya \& Yanmaz, 2005). A exemplo de outras brássicas, esta espécie apresenta alto teor de água e baixo teor de lipídeos, carboidratos e propriedades calóricas (Vilar et al., 2008). Também, tem como características, ação anticarcinogênica, uma vez que é rica em glucosinolatos e contém elevados teores de flavonóides, vitaminas e nutrientes minerais (Moreno et al., 2006).
\end{abstract}

Por ser uma cultura rústica, que se adapta a diferentes condições ambientais, a couve não necessita de alto nível tecnológico para o seu cultivo (Vilar et al., 2008). No entanto, é necessário um intenso trabalho de melhoramento para esta cultura, principalmente para aumentar a produtividade de folhas com padrão comercial e melhorar a sua resistência ao ataque de Brevicoryne brassicae e Plutella xylostella que são as principais pragas das brássicas (Lovatto et al., 2004; Boiça Júnior et al., 2010).

Existem muitos recursos genéticos que podem ser utilizados no melhoramento da couve, porém, há a possibilidade de se perder cultivares antigas devido à modernização das técnicas produtivas, mudanças socioeconômicas e pela introdução de novas cultivares (Laghetti et al., 2005; Gepts, 2006; Christensen et al., 2011). Desta forma, há necessidade de se caracterizar os genótipos de couve quanto aos seus caracteres agronômicos, variabilidade genética e mantê-los para futuros programas de melhoramento.

Atualmente, pesquisadores de vários países estão considerando a necessidade de estudar a divergência genética existente nas brássicas, dos quais podem-se citar a Índia (Vaishnava et al., 2006; Khan et al., 2009), Paquistão (Yousuf et al., 2011), Etiópia (Belete et al., 2011), Turquia (Okumus \& Balkaya, 2007), Bangladesh (Nath et al., 2003; Khatun et al., 2010), Grécia (Koutita et al., 2008), Dinamarca, Suécia e Itália (Sjödin et al., 2008; Christensen et al., 2011), utilizando-se a análise multivariada como ferramenta no estudo da divergência. No entanto, no Brasil são raros os trabalhos que visam caracterizar a divergência genética da couve e de outras brássicas. 
Assim, objetivou-se com este trabalho caracterizar genótipos de couve do banco de germoplasma da UFVJM quanto aos seus caracteres morfológicos, visando estimar a divergência genética por meio de diferentes técnicas de análise multivariada e verificar a importância das características avaliadas para o estudo de divergência.

\section{MATERIAL E MÉTODOS}

O experimento foi conduzido no Setor de Olericultura, localizado no campus JK da Universidade Federal dos Vales do Jequitinhonha e Mucuri (UFVJM) (18 12'01's, 4334'20'O, altitude de $1387 \mathrm{~m}$ ). No período de condução do experimento, a temperatura média foi de $18,3^{\circ} \mathrm{C}$ com umidade relativa do ar de $80,3 \%$, havendo poucas oscilações no decorrer deste período.

O delineamento experimental utilizado foi em blocos casualizados, com quatro repetições e cinco plantas por parcela. Foram avaliados 30 genótipos de couve do banco de germoplasma da UFVJM, sendo 19 genótipos oriundos de coletas em propriedades rurais na região de Diamantina-MG (UFVJM-2, UFVJM-3, UFVJM-4, UFVJM-5, UFVJM-7, UFVJM-8, UFVJM-9, UFVJM-10, UFVJM-13, UFVJM-19, UFVJM-21, UFVJM-22, UFVJM-24, UFVJM-26, UFVJM-27, UFVJM-30, UFVJM-32, UFVJM-34 e UFVJM-36), oito genótipos doados pela Universidade Federal de Lavras (UFLA-1, UFLA-3, UFLA-6, UFLA-8, UFLA-5, UFLA-10, UFLA-11 e UFLA-12) e três cultivares comerciais: couve-manteiga 900 legítima pé alto (Feltrin Sementes, Farroupilha-RS); couve-manteiga Baby (Vidasul Sementes Ltda., Xanxerê-SC) e couve-de-folha Manteiga Geórgia (Horticeres Sementes Ltda., Indaiatuba-SP).

No dia 28 de julho de 2011 foram coletadas brotações laterais no terço basal das plantas matrizes, com três a quatro centímetros de altura e dois folíolos para a formação das mudas pelo sistema de estaquia verde.

As brotações foram plantadas em bandejas de isopor de 72 células, preenchidas com substrato comercial Planti$\max ^{\circledR}$ e mantidas em casa de vegetação no Setor de Olericultura da UFVJM por 30 dias, com a finalidade de proporcionar o enraizamento. Após o enraizamento as mudas foram transplantadas para vasos com capacidade de $7,5 \mathrm{~kg}$ de solo preenchidos com Latossolo Vermelho distrófico e esterco bovino na proporção 3:1. Os vasos foram mantidos em casa de vegetação por 30 dias com objetivo de pegamento das mudas. Em 28 de setembro de 2011 os vasos foram levados para o campo, onde permaneceram até a coleta dos dados para a caracterização morfológica. As adubações de solo e cobertura foram realizadas de acordo com as recomendações para a cultura (Filgueira, 2008). Duas vezes por semana, foram retiradas as folhas senescentes e as brotações para possibilitar o melhor desenvolvimento das plantas.

No dia 2 de janeiro de 2012, foram avaliados individualmente, a altura das plantas (utilizando fita métrica graduada em cm, partir do nível do solo até a extremidade das folhas mais altas); o diâmetro do caule (em mm, medido com paquímetro na metade da altura da planta); o número de folhas apropriadas para a comercialização (contagem das folhas maiores que $15 \mathrm{~cm}$ e sem sinais de senescência); o número total de folhas na planta (contagem de todas as folhas desconsiderando as não expandidas e as folhas existentes nas brotações); o número de brotações e o número de pulgões adultos (Brevicoryne brassicae) e de lagartas (Plutella xylostella) de $4^{\mathrm{a}}$ instar presentes em todas as folhas da planta. $\mathrm{Na} 5^{\mathrm{a}}$ folha expandida, mais nova, foram avaliados o diâmetro da base e do centro do pecíolo em $\mathrm{mm}$ (medido com paquímetro na metade de sua extensão); o comprimento do pecíolo (medido com régua graduada em $\mathrm{cm}$ a partir de sua inserção no caule até o inicio do limbo foliar); o comprimento e largura do limbo foliar (utilizando régua graduada $\mathrm{em} \mathrm{cm}$ ); a área foliar $\mathrm{em}^{2}$ (coleta da $5^{\mathrm{a}}$ folha expandida mais nova de cada planta que compõe a parcela e, escaneada utilizando um Scanner HP Photosmart C4480, totalizando 5 folhas por repetição, sendo sua área estimada com o auxilio do software Image Pro Plus 4.5); e o peso da matéria seca em estufa com ventilação forçada de ar a $65^{\circ} \mathrm{C}$ até atingir peso constante.
Para a caracterização qualitativa dos genótipos utilizou-se escala de notas. Para isso, a $5^{\mathrm{a}}$ folha expandida mais nova de cada planta foi coletada e levada para o Laboratório de Olericultura, sendo em seguida avaliada por cinco avaliadores previamente treinados: o formato do limbo foliar, formato da margem foliar, formato do ápice foliar, formato da base foliar, base do pecíolo, proporção da projeção alada e tonalidade de verde, roxo e amarelo da parte adaxial e abaxial do pecíolo, da nervura principal, da nervura secundária e do limbo foliar seguindo a escala de notas apresentada na Figura 1.

Os dados obtidos por contagem e pontuação foram submetidos à transformação $\sqrt{X+1}$ com a finalidade de atender as pressuposições da análise de variância.

Para a aplicação do método de agrupamento de otimização de Tocher citado por Rao (1952), foi utilizada a distância generalizada de Mahalanobis $\left(\mathrm{D}^{2}\right)$ como medida de dissimilaridade. $\mathrm{O}$ dendrograma ilustrativo do padrão de dissimilaridade obtido pelo método UPGMA (Unweighted Pair Group Method with Arithmetic Mean) também foi utilizado no estudo da diversidade genética entre os genótipos. Tal procedimento permite avaliar melhor a divergência, confrontando os resultados obtidos por diferentes metodologias de análise multivariada, possibilitando interpretação mais precisa dos resultados e evitando possíveis equívocos. A importância dos caracteres para a discriminação da divergência foi verificada por intermédio da avaliação da contribuição relativa de cada característica para a divergência genética, estimados pelo método proposto por Singh (1981).

As análises uni e multivariadas foram realizadas utilizando-se o aplicativo genético-estatístico Genes (Cruz, 2006).

\section{RESULTADOS E DISCUSSÃO}

As medidas de dissimilaridade genética (Tabela 1), estimadas a partir da distância generalizada de Mahalanobis $\left(\mathrm{D}^{2}\right)$, apresentaram uma variação de 15,25 a 661,90 o que, segundo Benitez et al. (2011), indica a presença de ampla 


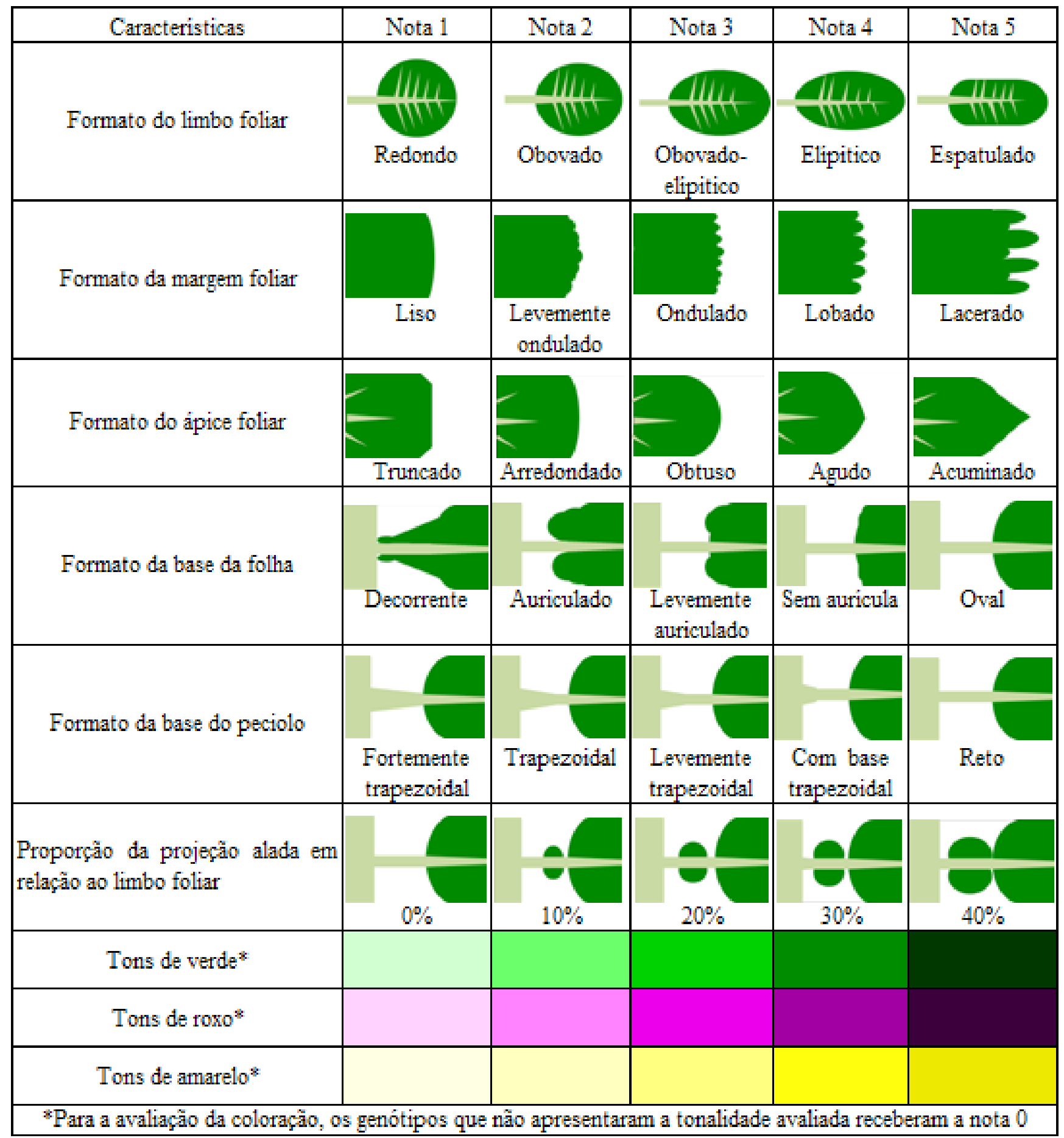

Figura 1. Escala de notas para as características avaliadas na folha em genótipos de couve (scale of scores for the evaluated traits in leaf of kale genotypes). Diamantina, UFVJM, 2012.

divergência genética entre os genótipos estudados. Estes dados são concordantes com os de Khan et al. (2009) que também avaliaram genótipos de couve.

Os genótipos UFLA-3 e UFLA-6 foram os mais divergentes entre si $\left(D^{2}=661,90\right)$, seguido dos genótipos UFVJM-10 e UFLA-24 $\left(\mathrm{D}^{2}=632,78\right)$, enquanto que os genótipos COM-1 e
COM-3 foram os menos divergentes $\left(\mathrm{D}^{2}=15,25\right)$, seguidos dos genótipos UFVJM-34 e UFVJM-22 ( $\left.{ }^{2}=22,60\right)$. O genótipo UFLA-6 esteve presente em nove combinações, apresentando-se como o mais divergente em relação aos demais, seguido do genótipo UFVJM-24 que esteve presente em oito combinações. Estes genótipos podem ser usados em cruzamentos bi-parentais uma vez que, pelo contraste dos mesmos (maior divergência genética), poderão potencializar a obtenção de populações altamente segregantes com possibilidade da obtenção de genótipos transgressivos para múltiplas características (Belete et al., 2011).

A análise de agrupamentos pelo mé- 
Tabela 1. Estimativas para a distância dos genótipos de couve mais próximos e mais distantes, baseados nas distâncias generalizadas de Mahalanobis $\left(\mathrm{D}^{2}\right)$ [estimates for the distance of the most similar and the most distant genotypes of kale, based on generalized Mahalanobis distances $\left(\mathrm{D}^{2}\right)$ ]. Diamantina, UFVJM, 2012.

\begin{tabular}{|c|c|c|c|c|}
\hline Genótipo & Menor $D^{2}$ & Genótipo mais próximo & Maior $D^{2}$ & Genótipo mais distante \\
\hline UFVJM-2 & 34,86 & UFVJM-26 & 392,19 & UFVJM-24 \\
\hline UFVJM-3 & 47,32 & UFLA-6 & 622,93 & UFLA-3 \\
\hline UFVJM-4 & 30,16 & UFVJM-36 & 328,42 & UFLA-6 \\
\hline UFVJM-5 & 45,93 & UFVJM-4 & 315,49 & UFVJM-24 \\
\hline UFVJM-7 & 59,26 & UFVJM-19 & 416,29 & UFLA-6 \\
\hline UFVJM-36 & 30,16 & UFVJM-4 & 401,26 & $\mathrm{COM}-2$ \\
\hline UFVJM-9 & 41,59 & UFVJM-2 & 334,05 & UFVJM-24 \\
\hline UFVJM-10 & 83,77 & UFLA-1 & 632,78 & UFVJM-24 \\
\hline UFVJM-13 & 44,29 & UFVJM-19 & 532,15 & UFLA-6 \\
\hline UFVJM-19 & 44,29 & UFVJM-13 & 455,60 & UFLA-6 \\
\hline UFVJM-21 & 52,13 & UFLA-1 & 499,83 & UFLA-6 \\
\hline UFVJM-22 & 22,60 & UFVJM-34 & 328,48 & COM-2 \\
\hline UFVJM-24 & 171,83 & UFLA-12 & 632,78 & UFVJM-10 \\
\hline UFVJM-26 & 34,86 & UFVJM-2 & 396,40 & UFVJM-24 \\
\hline UFVJM-27 & 55,22 & UFVJM-30 & 349,14 & UFVJM-24 \\
\hline UFVJM-30 & 38,47 & UFVJM-22 & 320,81 & UFVJM-24 \\
\hline UFVJM-32 & 30,54 & UFVJM-4 & 370,13 & UFVJM-24 \\
\hline UFVJM-34 & 22,60 & UFVJM-22 & 376,03 & $\mathrm{COM}-2$ \\
\hline UFVJM-8 & 59,29 & UFVJM-4 & 388,83 & UFLA-6 \\
\hline COM-1 & 15,25 & COM-3 & 515,70 & UFLA-11 \\
\hline COM-2 & 213,61 & UFVJM-5 & 525,40 & UFLA-5 \\
\hline COM-3 & 15,25 & COM-1 & 529,10 & UFLA-11 \\
\hline UFLA-1 & 52,13 & UFVJM-21 & 474,71 & UFLA-6 \\
\hline UFLA-3 & 118,46 & UFVJM-10 & 661,90 & UFLA-6 \\
\hline UFLA-6 & 47,32 & UFVJM-3 & 661,90 & UFLA-3 \\
\hline UFLA-8 & 99,54 & UFLA-12 & 351,88 & UFLA-6 \\
\hline UFLA-5 & 41,38 & UFLA-10 & 525,40 & COM-2 \\
\hline UFLA-10 & 41,38 & UFLA-5 & 471,74 & $\mathrm{COM}-2$ \\
\hline UFLA-11 & 96,11 & UFLA-12 & 529,10 & COM-3 \\
\hline UFLA-12 & 96,11 & UFLA-11 & 353,93 & COM-3 \\
\hline
\end{tabular}

todo de Tocher (Tabela 2), possibilitou a separação dos 30 genótipos em seis grupos distintos, verificando-se a presença de $77 \%$ dos genótipos no primeiro grupo, o que indica que embora haja genótipos com grande divergência genética entre si, a maioria é similar, o que segundo Silva et al. (2011) evidencia uma base genética estreita. $\mathrm{O}$ mesmo foi observado por diversos autores em diferentes culturas: Sudré et al. (2005) ava- liando pimenta e pimentão; Vaishnava et al. (2006) avaliando mostarda-amarela; Nunes et al. (2011a) avaliando linhagens de melão "pele de sapo"; Nunes et al. (2011b) avaliando linhagens de melão do grupo Inodorus; Silva et al. (2011) avaliando cana-de-açúcar.

A observação de ocorrência de mudanças abruptas nos agrupamentos e o conhecimento prévio dos genótipos foram utilizados como critérios para a formação de grupos no dendrograma (Figura 2). Considerou-se como corte a distância de $55 \%$, o que possibilitou a formação de seis grupos. Observou-se que os genótipos COM-2, UFVJM-10, UFLA-3, UFVJM-24, UFVJM-3 e UFLA-6 se mantiveram agrupados no dendograma (Figura 2), da mesma forma quando avaliados pelo método Tocher. No entanto, os genótipos pertencentes ao grupo I formado pelo método Tocher, 
Tabela 2. Agrupamentos formados com base no método de Tocher com base na distância generalizada de Mahalanobis em genótipos de couve (groups formed based on Tocher method based on Mahalanobis generalized distance in genotypes of kale). Diamantina, UFVJM, 2012.

\begin{tabular}{ll}
\hline Grupo & \multicolumn{1}{c}{ Genótipos } \\
\hline \multicolumn{3}{l}{1} & COM-1, COM-3, UFVJM-30, UFVJM-32, UFVJM-2, UFVJM-34, UFVJM-22, UFVJM-9, UFVJM-26, \\
& UFVJM-4, UFVJM-5, UFVJM-36, UFVJM-8, UFVJM-27, UFVJM-19, UFVJM-13, UFVJM-7, UFLA-1, \\
2 & UFVJM-21, UFLA-10, UFLA-8, UFLA-5, UFLA-12 \\
3 & UFVJM-3, UFLA-6 \\
4 & UFVJM-10, UFLA-3 \\
5 & UFLA-11 \\
6 & COM-2 \\
\hline
\end{tabular}

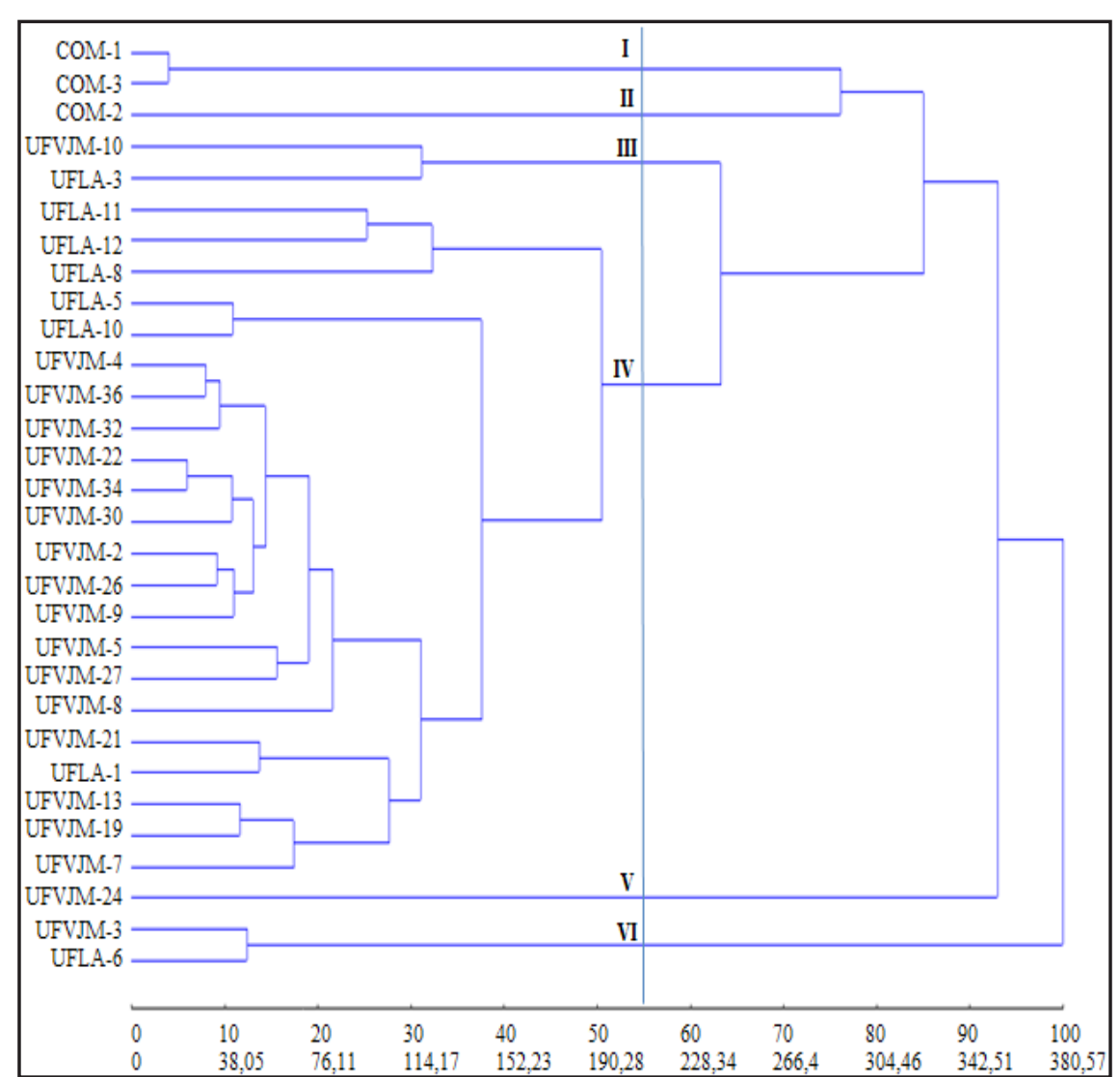

Figura 2. Dendrograma ilustrativo do padrão de dissimilaridade obtido pelo método UPGMA, com base na distância de Mahalanobis em genótipos de couve (dendrogram illustrating the standard of dissimilarity obtained by the UPGMA method, on the basis of the Mahalanobis distance in genotypes of kale). Diamantina, UFVJM, 2012.

que antes eram similares se dividiram em dois grupos no dendograma. Diferenças para a estimação da divergência genética entre o método Tocher e o dendograma, também foram observadas por outros autores como Sudré et al. (2005), Ivoglo et al. (2008), Nunes et al. (2011a, 2011b), o que é natural, uma vez que os métodos se fundamentam em técnicas maior produtividade, reduzindo a necessidade de tutoramento e facilitando os tratos culturais (Azevedo et al., 2012).

Em termos de contribuição relativa para a divergência genética (Tabela 3) constatou-se que as características mais importantes quanto à discriminação dos genótipos foram: comprimento do pecíolo $(9,81 \%)$, proporção da projeção alada $(8,77 \%)$, tom de roxo da superfície adaxial da nervura primária $(7,77 \%)$, formato da margem foliar $(7,49 \%)$, número de folhas totais $(6,89 \%)$, formato da base da folha $(5,93 \%)$ e diâmetro da base do pecíolo (5,26\%), o que configura a importância destes caracteres neste tipo de estudo. Por outro lado, com exceção do tom roxo das superfícies abaxial e adaxial, a coloração das folhas foi a característica que menos contribuiu para a divergência genética (Tabela 3). Os tons de verde do pecíolo na superfície abaxial $(0,10 \%)$, tons de amarelo do limbo na superfície adaxial $(0,10 \%)$ e tons de verde da nervura primária na superfície adaxial $(0,02 \%)$ foram as características que menos contribuíram. Este fato pode ser justificado pela pequena divergência genética para estas características, pela influência da variação ambiental, ou pela ineficácia da avaliação visual por escala de notas.

Concluiu-se que há divergência genética entre os genótipos de couve estudados e que há características importantes que podem ser usadas nas estimativas da divergência.

\section{AGRADECIMENTOS}

À FAPEMIG, ao CNPq e à CAPES 
Tabela 3. Contribuição relativa (\%) de características para a divergência genética em genótipos de couve, estimados pelo método proposto por Singh (1981) [relative contribution (\%) of characteristics for genetic divergence in genotypes of kale estimated by the method proposed by Singh (1981)]. Diamantina, UFVJM, 2012.

\begin{tabular}{|c|c|c|c|}
\hline Características & S. j (\%) & Características & S. j (\%) \\
\hline Formato do limbo foliar & 2,34 & Tom de verde do pecíolo (adaxial) & 1,88 \\
\hline Formato da margem foliar & 7,49 & Tom de verde do limbo (adaxial) & 1,90 \\
\hline Formato do ápice foliar & 2,02 & Tom de verde da nervura $1^{\mathrm{a}}$ (adaxial) & 0,02 \\
\hline Formato da base da folha & 5,93 & Tom de verde da nervura $2^{\mathrm{a}}$ (adaxial) & 0,28 \\
\hline Formato da base do pecíolo & 1,46 & Tom de roxo do pecíolo (adaxial) & 3,17 \\
\hline Proporção da projeção alada & 8,77 & Tom de roxo do limbo (adaxial) & 0,67 \\
\hline Comprimento da folha & 1,37 & Tom de roxo da nervura $1^{\text {a }}$ (adaxial) & 7,77 \\
\hline Largura da folha & 1,53 & Tom de roxo da nervura $2^{\text {a }}$ (adaxial) & 0,26 \\
\hline Comprimento do pecíolo & 9,81 & Tom de amarelo do pecíolo (adaxial) & 0,58 \\
\hline Diâm. do centro do pecíolo & 1,84 & Tom de amarelo do limbo (adaxial) & 1,84 \\
\hline Diam. da base do pecíolo & 5,26 & Tom de amarelo da nervura $1^{\text {a }}$ (adaxial) & 0,48 \\
\hline Área foliar & 0,76 & Tom de amarelo da nervura $2^{\text {a }}$ (adaxial) & 0,42 \\
\hline Massa seca por folha & 2,82 & Tom de verde do pecíolo (abaxial) & 0,10 \\
\hline Altura da planta & 5,14 & Tom de verde do limbo (abaxial) & 0,93 \\
\hline Diâmetro do caule & 1,36 & Tom de verde da nervura $1^{a}$ (abaxial) & 0,15 \\
\hline Núm. de folhas comerciais & 0,89 & Tom de verde da nervura $2^{\mathrm{a}}$ (abaxial) & 2,20 \\
\hline Núm. folhas totais & 6,89 & Tom de roxo do pecíolo (abaxial) & 0,53 \\
\hline Número de brotações & 2,02 & Tom de roxo do limbo (abaxial) & 0,32 \\
\hline Número de pulgões & 0,97 & Tom de roxo da nervura $1^{\text {a }}$ (abaxial) & 3,97 \\
\hline \multirow[t]{5}{*}{ Número de lagartas } & 0,81 & Tom de roxo da nervura $2^{\text {a }}$ (abaxial) & 0,81 \\
\hline & & Tom de amarelo do pecíolo (abaxial) & 0,74 \\
\hline & & Tom de amarelo do limbo (abaxial) & 0,10 \\
\hline & & Tom de amarelo da nervura $1^{\text {a }}$ (abaxial) & 0,24 \\
\hline & & Tom de amarelo da nervura $2^{\text {a }}$ (abaxial) & 1,18 \\
\hline
\end{tabular}

pela concessão de bolsas de estudos e recursos financeiros para o desenvolvimento do projeto. À HortiAgro Sementes pela disponibilização dos genótipos de couve código UFLA.

\section{REFERÊNCIAS}

AZEVEDO AM; ANDRADE JÚNIOR VC; PEDROSA CE; FERNANDES JSC; VALADARES NR; FERREIRA MAM; MARTINS RAV. 2012. Desempenho agronômico e variabilidade genética em genótipos de couve. Pesquisa Agropecuária Brasileira 47: 1751-1758.

BALKAYAA; YANMAZ R. 2005. Promising kale (Brassica oleracea var. acephala) populations from Black Sea region, Turkey. New Zealand Journal of Crop and Horticultural Science 33: 1-7.

BELETE YS; KEBEDE SA; GEMELAL AW. 2011. Multivariate analysis of genetic divergence among Ethiopian Mustard (Brassica carinata A. Brun) genotypes in relation to seed oil quality traits. International
Journal of Agricultural Research 6: 494-503. BENITEZ LC; RODRIGUES ICS; ARGE LWP; RIBEIRO MV; BRAGA EJB. 2011. Análise multivariada da divergência genética de genótipos de arroz sob estresse salino durante a fase vegetativa. Revista Ciência Agronômica 42: 409-416.

BOIÇA JUNIOR AL; CHAGAS FILHO NR; SOUZA JR. 2010. Não-preferência para oviposição de traça-das-crucíferas em genótipos de couve-flor. Revista Caatinga 23: 28-33.

CHRISTENSEN S; BOTHMER RV; POULSEN G; MAGGIONI L; PHILLIP M; ANDERSEN BA; JØRGENSEN RB. 2011. AFLP analysis of genetic diversity in leafy kale (Brassica oleracea L. convar. acephala (DC.) Alef.) landraces, cultivars and wild populations in Europe. Genet Resour Crop Evol 58: 57-666.

CRUZ CD. 2006. Programa GENES: Aplicativo computacional em genética e estatística versão Windows. Viçosa: UFV. 382 p.

FILGUEIRA FAR. 2008. Novo manual de olericultura: Agrotecnologia moderna na produção e comercialização de hortaliças. Viçosa: UFV. 402p.

GEPTS P. 2006. Plant genetic resources conservation and utilization: the accomplishments and future of a societal insurance policy. Crop Science 46: 2278-2292.

IVOGLO MG; FAZUOLI LC; OLIVEIRAACB; GALLO PB; MISTRO JC; SILVAROLLAMB; TOMA-BRAGHINI M. 2008. Divergência genética entre progênies de café robusta. Bragantia 67: 823-83.

KHAN SH; AHMED N; JABEEN N; MUSHTAK F; HSSAIN K. 2009. Genetic divergence in kale (Brassica oleracea var. acephala L.) S.H. The Asian Journal of Horticulture 4: 134-137.

KHATUN H; RASUL MG; SAIKAT MMH; HAQUE MM. 2010. Genetic diversity in Brassica rapa L. Bangladesh J. Pl. Breed. Genet. 23: 31-37.

KOUTITA O; TERTIVANIDIS K; KOUTSOS T; KOUTSIKA-SOTIRIOU M; SKARACIS G. 2008. Genetic changes between $\mathrm{C}_{0}, \mathrm{C}_{3}$, $\mathrm{C}_{5}$ cycles of selection and $\mathrm{S}_{4}$ lines of two cabbage (Brassica oleracea L. var. capitata L.) open pollinated populations based on RAPD markers. Biotechnology 7: 475-480.

LAGHETTI G; MARTIGNANO F; FALCO V; CIFARELLI S; GLADIS T; HAMMER K. 2005. "Mugnoli": a neglected race of Brassica oleracea L. from Salento (Italy). Genet Resour Crop Evol 52: 635-639. 
LOVATTO PB; GOETZE M; THOMÉ GCH. 2004. Efeito de extratos de plantas silvestres da família Solanaceae sobre o controle de Brevicoryne brassicae em couve (Brassica oleracea var. acephala). Ciência Rural 34: 971-978.

MORENO DA; CARVAJAL M; LOPEZBERENGUER C; GARCIA-VIGUERA C. 2006. Chemical and biological characterization of nutraceutical compounds of broccoli. Journal Pharm Biomed Anal 41: 1508-22.

NATH UK; NAZ S; RAHMAN MM. 2003. Genetic divergence of Brassica campestris, Brassica juncea parents and their hybrids. Pakistan Journal of Biological Sciences 6: 936-938.

NUNES GH; COSTA FILHO JA; SILVA DJH; CARNEIRO PCS; DANTAS DJ. 2011a. Divergência genética entre linhagens de melão Pele de Sapo. Revista Ciência Agronômica 42: 765-773.

NUNES GH; MELO DRM; DANTAS DJ; ARAGÃO FAS; NUNES EWL. 2011b.
Divergência genética entre linhagens de melão do grupo Inodorus. Revista Ciência Agronômica 42: 448-456.

OKUMUS A; BALKAYA A. 2007. Estimation of genetic diversity among Turkish kale populations (Brassica oleracea var. acephala L.) using RAPD markers. Russian Journal of Genetics 43: 411-415.

RAO RC. 1952. Advanced statistical methods in biometric research. New York: John Wiley and Sons. 390p.

SILVA GC; OLIVEIRA FJ; ANUNCIAÇÃO FILHO CJ; NETO DES; MELO LJOT. 2011. Divergência genética entre genótipos de canade-açúcar. Revista Brasileira de Ciências Agrárias 6: 52-58.

SINGH D. 1981. The relative importance of characters affecting genetic divergence. Indian Journal of Genetic and Plant Breeding 11: 237-245.

SJÖDIN P; HEDMAN H; KRUSKOPF OSTERBERG M; GUSTAFSSON S;
LAGERCRANTZ U; LASCOUX M. 2008. Polymorphism and divergence at three duplicate genes in Brassica nigra. Journal of Molecular Evolution 66: 581-590.

SUDRÉ CP; RODRIGUES R; RIVA EM; KARASAWA M; AMARAL JÚNIOR AT. 2005. Divergência genética entre acessos de pimenta e pimentão utilizando técnicas multivariadas. Horticultura Brasileira 23: 22-27.

VAISHNAVA A; SACHAN JN; TEWARI SK. 2006. Genetic divergence for important quantitative traits in Indian mustard \{ Brassica juncea (1.) czern and coss $\}$. Agricultural Science Digest 26: 269-272.

VILAR M; CARTEA ME; PADILLA G. 2008. The potential of kales as a promising vegetable crop. Euphytica 159: 153-165.

YOUSUF M; AJMAL SU; MUNIR M; GHAFOOR A. 2011. Genetic diversity analysis for agro-morphological and seed quality traits in rapeseed (Brassica campestris L.). Pakistan Journal of Botany 43: 1195-1203. 